\title{
Analysis of spatial and temporal variability in interactions among algae, limpets and mussels in low-shore habitats on the west coast of Italy
}

\author{
Lisandro Benedetti-Cecchi*, Silvio Nuti, Francesco Cinelli
}

Dipartimento di Scienze dell'Ambiente e del Territorio, Università di Pisa, Via A. Volta 6, I-56126 Pisa, Italy

\begin{abstract}
Spatial and temporal variation in interactions between algae, limpets (Patella spp.) and mussels (Mytilus galloprovincialis) were examined in low-shore habitats south of Livorno, on the west coast of Italy (western Mediterranean), from August 1993 to February 1995. Experiments were set up to: (1) contrast the response of the length of fronds and coverage of the brown alga Cystoseira compressa to the removal of algal turfs and mussels in habitats dominated by these organisms; (2) test whether any effect of mussels on $C$. compressa was consistent in space (at scales ranging from 1 to $1000 \mathrm{~m}$ ) and as a function of the presence of limpets; (3) test for the temporal consistency in any effect of limpets on the development of macroalgae in habitat dominated by mussels and (4) test for spatial consistency in the temporal patterns of algal recovery in this habitat. Removal of the algal turfs had no effect on the length of fronds of $C$. compressa; no effect was observed on its coverage but this result was probably confounded by artifacts. In contrast, mussels had both positive and negative effects on $C$. compressa. The mean length of fronds of this alga was significantly reduced by the removal of mussels, this effect being particularly evident after a period of severe storms occurring soon after the initiation of the experiment. A possible mechanism to explain this could involve the stabilisation of the basal fronds of the plants, because mussels were often packed around them. Conversely, the coverage of $C$. compressa increased significantly after the removal of the mussels, this effect probably resulting from the inhibition of recruitment of the alga. The effects of mussels were consistent in space and almost independent of the presence of limpets. In contrast, the herbivores influenced the temporal changes in abundance of the coarsely-branched algae and articulated corallines, but not those of the filamentous and foliose algae or of $C$. compressa. Finally, no space-time interactions were found in the analyses of variance, indicating that the course of succession was consistent among areas distributed along a stretch of shore about $1.5 \mathrm{~km}$ in length. The results of this study suggest that the assemblage of species dominated by mussels on the rocky coasts south of Livorno was not a highly interactive system. Most of the biological processes investigated were consistent in space and/or in time.
\end{abstract}

KEY WORDS: Spatial variability · Temporal variability · Macroalgae Mussels C Competition - Grazing Rocky shores

\section{INTRODUCTION}

The importance of interspecific interactions in influencing the spatial and temporal distribution of plants and animals on rocky shores is widely acknowledged. Competition for space and trophic interactions are among the most common processes investigated (Connell 1983, Sih et al. 1985, Underwood 1986, John et al. 1992). Competition in the form of pre-emption of the

•E-mail: bencecc@discat.unipi.it substratum may explain differences between habitats in the distribution of algal populations (e.g. Dayton 1973, Paine 1979), and the variability in patterns of succession (Sousa 1985 and references therein). The foraging activity of carnivores and herbivores may affect the distribution of organisms either through direct effects or through indirect pathways involving alteration of competitive interactions (Lubchenco 1978 , Hawkins \& Hartnoll 1983, Wootton 1992, Menge 1995).

The physical environment may modify the strength and importance of biological interactions, and the inter- 
play between abiotic and biotic factors is a topic of considerable current ecological interest (Menge \& Sutherland 1987, Danielson 1991). Several relevant examples come from studies of predation on rocky shores, where the effects of a particular predator are contrasted along gradients of wave exposure (Menge 1976, 1978, Fairweather \& Underwood 1991) or tidal height (Robles et al. 1995). The consistency of a particular interaction within the same habitat is, however, examined less frequently, but knowledge of this source of variability is necessary whenever comparisons across habitats or locations are made (Hurlbert 1984, Underwood \& Petraitis 1993). Examining spatial patterns at small scales is also important because patchiness is a feature of many natural systems, but the underlying ecological processes are not fully appreciated (e.g. Chapman 1995).

The interplay between physical and biological processes may also take the form of changes in the strength of interactions among organisms over time. The physical and biological features of a given habitat are likely to change with time, influencing the biology and behaviour of resident populations. Studies of succession on rocky shores provide some examples of temporal shifts in the relevance of trophic or competitive interactions among species. The effect of limpets on macroalgae, for instance, is supposed to decrease at later stages of succession (Sousa 1979, 1984, Benedetti-Cecchi \& Cinelli 1996). This is often inferred from the observation that the density of limpets in artificial clearings may decrease with time, possibly as a consequence of increased competition for space with macroalgae (e.g. Underwood \& Jemakoff 1981). These effects, however, have been deduced mostly from inspection of graphs or analyses on data which were not independent through time (but see Sousa 1979, Arrontes \& Underwood 1991). This form of nonindependence might have precluded a correct test of statistical interactions between time and competitive or grazing effects (see discussion in Underwood \& Anderson 1994 for similar problems).

In this study, we have examined spatial and temporal variations in the interactions between algae, limpets and mussels in 2 of the most common habitats occurring low on the shore on the west coast of Italy (western Mediterranean): areas dominated by mussels and areas colonized by algal turfs. Since we had no a priori expectation of whether or how these interactions could vary, we tested the general null hypothesis of no spatial and temporal variability in their outcomes. The brown alga Cystoseira compressa (Esper) Gerloff \& Nizamuddin provided the response variable in most of the experiments, because it was common in both habitats and could be easily monitored. In addition, plants of the genus Cystoseira are the most common canopy-forming algae on the Mediterranean coasts providing a comparable system with those investigated in other parts of the world. Specifically, experiments were set up to test: (1) the hypothesis that the length of fronds and coverage of $C$. compressa would change in response to the removal of algal turfs and mussels in habitats dominated by these organisms; (2) the null hypothesis that any effect of mussels on $C$. compressa would be consistent in space and the hypothesis that the effect of mussels would be different in the presence of limpets (the effect of limpets was examined only in mussel beds, because they were rare in areas densely covered by algal turfs); (3) the null hypothesis that there would be little consistency in any effect of limpets on the development of macroalgae in the habitat dominated by mussels; and (4) the null hypothesis that there would be little spatial consistency in the temporal patterns of algal recovery in this habitat (see Benedetti-Cecchi \& Cinelli 1994). Although mussel beds are locally abundant along the rocky coasts of the Mediterranean, very few studies have been made in this system. The present work is the first experimental investigation of interactions between mussels, limpets and algae in the Mediterranean basin

\section{MATERIALS AND METHODS}

Study site and organisms. This study was carried out on the exposed rocky shore south of Livorno, Italy $\left(43^{\circ} 30^{\prime} \mathrm{N}, 10^{\circ} 20^{\prime} \mathrm{E}\right.$ ), between July 1993 and February 1995. The experimental units were interspersed on sandstone platforms located from 0 to $-0.5 \mathrm{~m}$ below the mean low level water. Two major types of habitats occurred at these levels on the shore: areas dominated by algal turfs and areas monopolised by the mussel Mytilus galloprovincialis Lamarck (Benedetti-Cecchi \& Cinelli 1994). These habitats were interspersed on the shore producing spatial heterogeneity on a scale of between 10 and $50 \mathrm{~m}$.

The turf-forming algae were represented mainly by the articulated corallines Corallina elongata Ellis \& Solander and Halyptilon virgatum (Zanardini) Garbari \& Johansen which formed dense mats about 3 to $5 \mathrm{~cm}$ high. Other plants living within these mats included filamentous species (mainly Ceramium spp. and Polysiphonia spp.) and coarsely branched algae such as Chondria boryana (De Notaris) De Toni, Gastroclonium clavatum (Roth) Ardissone and Laurencia obtusa (Hudson) Lamoroux. Additional details on this habitat can be found in Benedetti-Cecchi \& Cinelli (1994).

The same species of algae characterising the turfing habitat also occurred at smaller densities in gaps within the mussel beds or as epiphytes on the mussels which themselves cover much of the primary space. Also the brown alga Cystoseira compressa, which 
formed dense populations with fronds up to $15 \mathrm{~cm}$ in length, was present in both habitats, but was more abundant in mussel beds (Benedetti-Cecchi et al. 1995).

Herbivores at these levels on the shore were mainly limpets (Patella aspera Roding and P. caerulea L.) which, although uncommon in the turfing habitat, were locally abundant on patches of bare rock or rock occupied by the encrusting base of Coralline elongata within the mussel beds. Sea urchins were abundant in nearby rockpools and sublittoral habitats but were never seen in the study areas.

Effects of algal turis on Cystoseira compressa. The effects of the algal turfs on the length of fronds and coverage of $C$. compressa were investigated from July 1993 to April 1994 in the turfing habitat. Sixteen plots $\left(20 \times 20 \mathrm{~cm}^{2}\right)$ were located in a large area dominated by algal turfs along $50 \mathrm{~m}$ of coast. Each plot had a clump of C. compressa in the middle which covered about $20 \%$ of the surface. The plots were marked at their corners with epoxy putty and were assigned at random to 1 of 2 treatments with 8 replicates each: control (no manipulation) or removal of turfs. The algal turfs were removed from the appropriate plots using a paint scraper, while $C$ compressa was left undisturbed. The percentage cover of each clump and the length of 3 replicate fronds chosen at random were measured in each plot every 2 or 3 mo. Percentage cover values were obtained using the pointintercept technique and the effect of the algal turf was assessed by Student's t-test. Fronds were measured to the nearest $\mathrm{mm}$ with plastic callipers. Lengths of fronds were analysed by a 2-way nested ANOVA with treatment fixed and plots nested in treatment as the random effect. Two separate analyses were done for each response variable: one in August 1993, 1 mo after the start of the experiment and the other in April 1994. These dates were considered because they represented peaks in the vegetative growth of $C$. compressa. The other dates were not analysed to limit inflation of the Type I error rate. The assumption of homogeneity of variances was assessed (here and in the following analyses) using Cochran's test (Winer 1971, Underwood 1981).

Effects of limpets and mussels on Cystoseira compressa. This experiment was done in the habitat dominated by mussels, and tested for the effects of limpets, mussels, their interaction and the spatial consistency of any effect of mussels on the coverage and length of fronds of $C$. compressa. The experiment also tested for the effect of mussels on the distribution of limpets. In July 1993, 6 areas (stretches of shore 15 to $20 \mathrm{~m}$ long) dominated by mussels were selected for the experiment along $\sim 1.5 \mathrm{~km}$ of coast. Limpets were removed by hand from 3 areas randomly chosen from the 6 areas. In each area, 6 experimental plots $(30 \times 30 \mathrm{~cm})$ were marked at their corners with epoxy putty. Each plot had a clump of C. compressa covering about $20 \%$ of the surface of a $20 \times 20 \mathrm{~cm}$ quadrat centered in it the remaining $80 \%$ of primary substratum was occupied by mussels). The plots were assigned at random to the following 3 treatments with 2 replicates each: (1) control (no manipulation); (2) removal of mussels from half the surface around the clump of $C$. compressa (hereafter HR); and (3) total removal of mussels (hereafter TR). Maintenance of this treatment required visits to the shore every 1 or $2 \mathrm{wk}$ for the entire duration of the investigation, which lasted until August 1994.

The percentage cover of Cystoseira compressa and the length of 3 fronds chosen at random were measured every 2 or 3 mo in each plot. Percentage cover values were obtained by sampling a $20 \times 20 \mathrm{~cm}$ quadrat centred in each plot using the point-intercept technique, while fronds were measured to the nearest mm using plastic callipers. Limpets were counted in each quadrat on 4 occasions (January, April, June and August 1994). The mean cover of $C$. compressa was analysed using a 3-way mixed model ANOVA with presence/absence of limpets and partial or total removal of mussels as fixed, orthogonal factors and areas as a random variable nested within presence or absence of limpets and orthogonal to mussels. The effects of mussels on limpets were assessed only in areas where herbivores were not removed (see 'Results: Effects of limpets and mussels on Cystoseira compressa') using a 2-way factorial ANOVA with control versus HR or TR fixed and areas random. Data on the length of fronds were analysed using a 4-way mixed model ANOVA with presence/absence of limpets and manipulation of mussels as fixed, orthogonal factors, areas as a random factor nested within limpet treatments and orthogonal to mussel treatments; plots were a random factor nested in each combination of mussel treatment $\times$ area. To limit inflation of the Type I error rate, only 2 dates were analysed for each response variable. The effects of treatments on the length of fronds and percent cover of C. compressa were examined in August 1993, 1 mo after the start of the experiment, and in June 1994. The first date of sampling was after a period of severe storms and provided the opportunity to test for the effect of mussels after severe wave action. The second date coincided with a peak in vegetative growth of $C$. compressa. The effects of treatments on the distribution of Patella spp. were examined in April and June 1994, because limpets were more active in these periods (L. Benedetti-Cecchi pers. obs.)

Recovery of algae in the mussel habitat. Patterns of algal recovery were examined in artificially cleared plots within the mussel beds from July 1993 until February 1995. The same areas used in the previous experiment were also employed in this case. These areas were large enough to keep all the experimental plots 50 to $100 \mathrm{~cm}$ apart. In each area, 6 plots of $20 \times 20 \mathrm{~cm}$ 
were cleared of mussels and algae with a paint scraper and a plastic brush. This size was chosen as representative of that of patches commonly produced by natural disturbances usually due to storms at this study site (authors' unpubl. data). The corners of each plot were marked with epoxy putty for subsequent relocation. Clearing caused removal of mussels and erect macroalgae, while encrusting corallines (and particularly the encrusting base of Corallina elongata) remained attached to the rock. The percentage cover of algae and the density of limpets were recorded in a 15 $\times 15 \mathrm{~cm}$ quadrat centred in each plot. To provide formal tests on the temporal course of the establishment of algae, limpet treatments $x$ time and space $\times$ time interactions had to be analysed. To ensure independent data at each time analysed, 2 replicate plots from each area were randomly assigned to each of the following 3 dates of sampling: (1) October 1993 (3 mo after start); (2) May 1994 (10 mo after start) and (3) February 1995 (19 mo after start). These dates were considered as representative of different stages of recovery, as predicted by the results of Benedetti-Cecchi \& Cinelli (1994) for the habitat dominated by the algal turfs. Therefore, in the present experiment, the data were gathered independently through time allowing the inclusion of this factor in the analyses. The data were analysed using a 3-way mixed model ANOVA with limpet treatments and time as fixed, orthogonal factors, and areas as a random variable nested within limpet treatments and orthogonal to times of sampling.

\section{RESULTS}

\section{Effects of algal turfs on Cystoseira compressa}

The occurrence of severe storms soon after the start of the experiment (in mid July 1993) prevented initial measurement of the length of fronds and percentage cover of Cystoseira compressa in the experimental plots. Because of randomization, there is no reason to expect initial differences between treatments and controls for these variables. Possibly as a consequence of disturbance by waves, the heights of plants of $C$. compressa were drastically reduced and the mean lengths of fronds never exceeded $35 \mathrm{~mm}$ throughout the study (Fig. 1A). The removal of the algal turfs had no effect on the length of fronds in August 1993 or in April 1994 (Table 1, Fig. 1A). In contrast, significant differences among plots occurred on both dates (Table 1).

The algal turfs had no apparent effect on the cover of Cystoseira compressa although a trend toward a lower
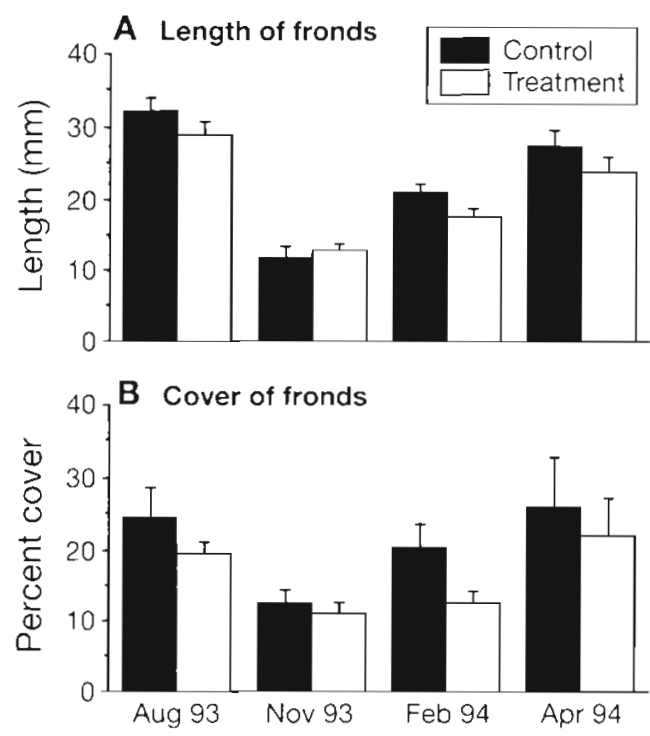

Fig. 1. Cystoseira cunpressa. Effects of remuval of aigal turis. (A) Mean length (+SE) of 3 replicate fronds pooled across 8 replicate plots in each treatment. (B) Mean percent covers $(+\mathrm{SE}, \mathrm{n}=8$ ) in control and treatment plots

abundance of this alga in treatment plots was evident (Fig. 1B). Mean percent covers did not differ significantly in August 1993 ( $t$-test: $t=0.9,14 \mathrm{df}, \mathrm{p}>0.05$ ) or in April 1994 ( $t$-test: $t=0.3,14 \mathrm{df}, \mathrm{p}>0.05$ ). It is worth noting that these tests considered only the cover of the clumps present in the plots from the beginning of the experiment: recruitment was not observed in treatment or in control plots, the former probably being overdisturbed due to the frequent scraping of the substratum necessary to prevent colonization by the algal turfs. Because the scraping procedure was not selective for the algal turfs and the outcome of the experiment was not such as to exclude the occurrence of artifacts, we did not regard this result as reliable (see 'Discussion').

\section{Effects of limpets and mussels on Cystoseira compressa}

Manual removal of limpets from 3 of the 6 areas allowed reduction, but not complete exclusion, of these

Table 1 ANOVA on the effects of algal turfs on the length of fronds of Cystoserra compressa

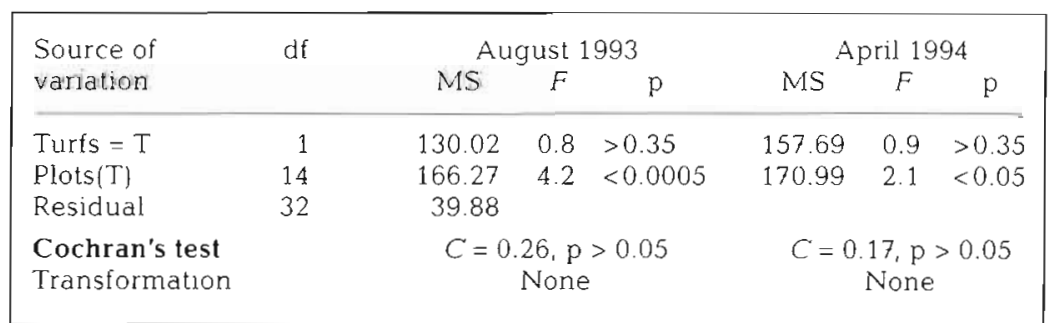


herbivores from the experimental plots. The abundance of limpets in the removal areas, expressed as the percentage of the number found in the areas where they were not removed (means and standard errors over 4 dates of sampling: January, April, June and August 1994) was $21.8 \pm 11.7,14.1 \pm 5$ and $25.9 \pm 15$ for control, HR and TR plots, respectively. A formal test on the efficacy of removal was not possible because variances were heterogeneous. Thus, the effects of mussels on limpets were examined only in the 3 areas exposed to natural densities of herbivores. Despite a trend toward a greater abundance of these herbivores in control plots (Fig. 2), no significant effect of mussels was found for the 2 dates analysed (April and June 1994), neither were there significant differences among areas or interactive effects between mussels and areas (April 1994: $F_{2.4}=0.7$, $p>0.50$ for the main effect of mussels, $F_{2,9}=2.9, p>0.10$ for the main effect of areas, and $F_{4,9}=1.8, p>0.20$ for the interaction. June 1994: $F_{2,4}=1.8, \mathrm{p}>0.25$ for the main effect of mussels, $F_{2,9}=3.7, p>0.05$ for the main effect of areas, and $F_{4,9}=1.4, \mathrm{p}>0.25$ for the interaction).

As in the previous experiment, the occurrence of storms in July 1993 prevented initial sampling of the length of fronds and cover of Cystoseira compressa in the experimental plots. The first date of sampling was in mid August 1993, after the storms ceased (Fig. 3). At that time, the length of fronds differed significantly among treatments and in relation to limpets (note the treatment by limpet interaction in Table 3 for August 1993). The SNK test revealed, as a general pattern, shorter fronds in TR and HR plots than in controls. TR and HR treatments were never significantly different, but the order of their means changed depending upon the abundance of limpets (Table 2). Inspection of graphs indicates that differences between treatments in the length of fronds decreased through time (Fig. 3). A significant treatment by limpet interaction was still present in June 1994 (Table 2). In this case, however, the SNK test could not identify an alternative to the null hypothesis for plots exposed to natural densities of limpets, while treatments did not differ in areas where Patella spp. had been removed (Table 2). Small-scale

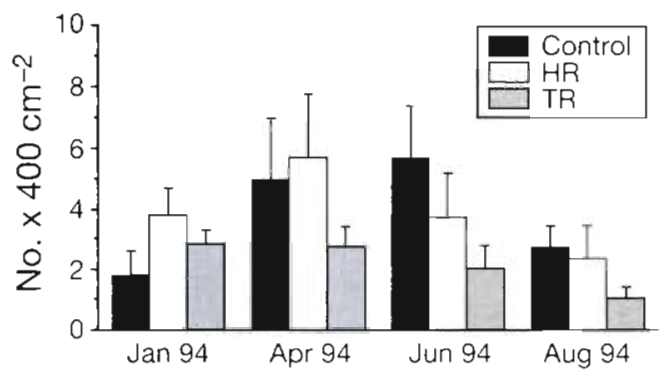

Fig. 2. Patella spp. Effects of removal of mussels on mean numbers $(+S E)$. from 2 replicate plots pooled across 3 replicate areas. HR: half removal plots; TR: total removal plots

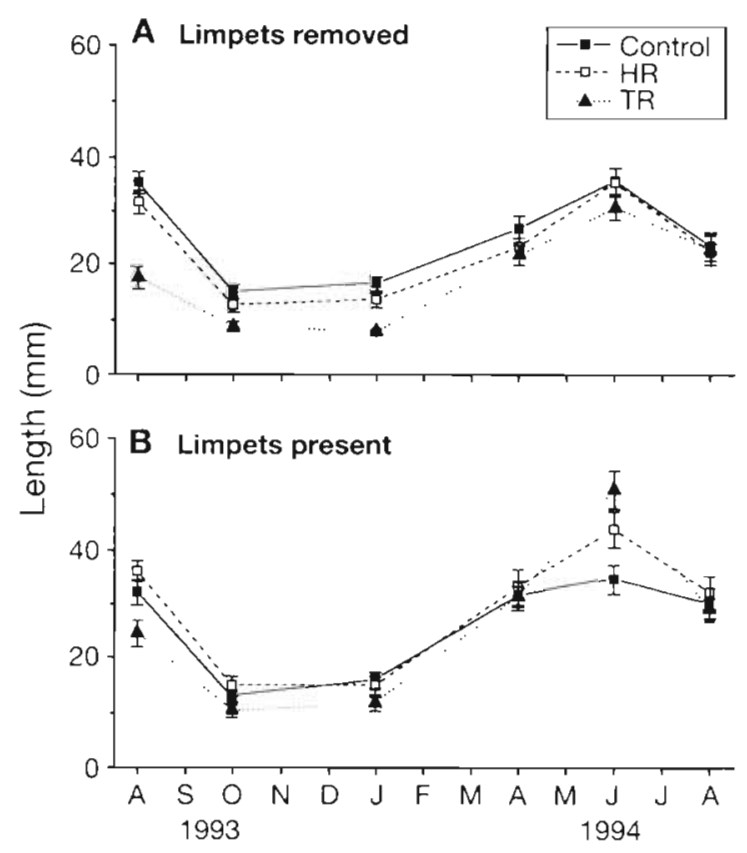

Fig. 3. Cystoseira compressa. Effects of removal of mussels and limpets on mean $( \pm S E)$ length of fronds. Data are from 3 replicate fronds pooled across 2 replicate plots and 3 replicate areas

variability (between plots) in the length of fronds was also large, particularly in June 1994 (Table 2).

The removal of mussels affected the cover of Cystoseira compressa, the magnitude of this effect increasing with time (Fig. 4). The abundance of C. compressa was significantly greater in TR and HR than in control plots in

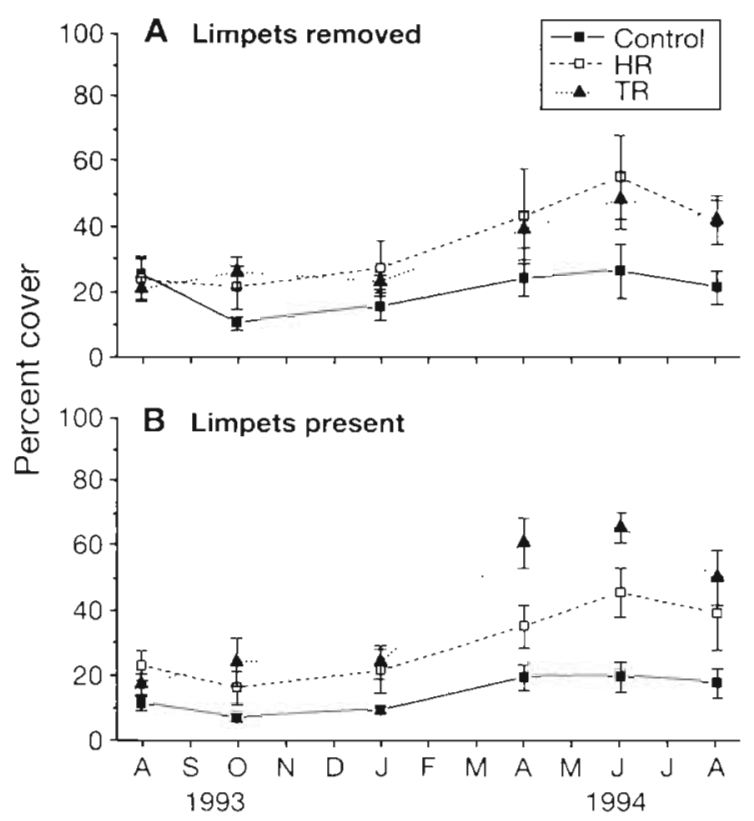

Fig. 4. Cystoseira compressa. Effects of removal of mussels and limpets on mean percent cover $( \pm S E$ ). Data are from 2 replicate plots pooled across 3 replicate areas 
Table 2. ANOVA of responses of length of fronds of Cystoseira compressa to the manipulation of limpets and mussels in different areas of substratum and in different plots within areas

\begin{tabular}{|c|c|c|c|c|c|c|c|}
\hline \multirow{2}{*}{$\begin{array}{l}\text { Source of } \\
\text { variation }\end{array}$} & \multirow[t]{2}{*}{$\mathrm{df}$} & \multicolumn{3}{|c|}{ August 1993} & \multicolumn{3}{|c|}{ June 1994} \\
\hline & & $\mathrm{MS}$ & $F$ & $\mathrm{p}$ & MS & $F$ & p \\
\hline Limpets $=\mathrm{L}$ & 1 & 166.26 & 0.50 & $>0.5$ & 2232.23 & 5.95 & $>0.05$ \\
\hline $\operatorname{Areas}(\mathrm{L})$ & 4 & 332.10 & 2.60 & $>0.05$ & 375.10 & 1.44 & $>0.25$ \\
\hline Mussels $=M$ & 2 & 1912.86 & 45.58 & $<0.0001$ & 324.62 & 1.66 & $>0.20$ \\
\hline $\mathrm{M} \times \mathrm{L}$ & 2 & 245.45 & 5.84 & $<0.05$ & 1033.23 & 5.29 & $<0.05$ \\
\hline $\mathrm{M} \times \operatorname{Areas}(\mathrm{L})$ & 8 & 41.96 & 0.33 & $>0.90$ & 195.34 & 0.75 & $>0.60$ \\
\hline $\operatorname{Plots}[M \times \operatorname{Areas}(\mathrm{L})]$ & 18 & 127.57 & 2.00 & $<0.05$ & 260.25 & 2.77 & $<0.01$ \\
\hline Residual & 72 & 63.68 & & & 93.84 & & \\
\hline $\begin{array}{l}\text { Cochran's test } \\
\text { Transformation }\end{array}$ & \multicolumn{4}{|c|}{$C=0.14, p>0.05$} & \multicolumn{3}{|c|}{$C=0.13, \mathrm{p}>0.05$} \\
\hline \multirow[t]{3}{*}{ SNK test } & & \multicolumn{3}{|c|}{$(M \times L: S E=1.53,8 d f)$} & \multicolumn{3}{|c|}{$(\mathrm{M} \times \mathrm{L}: \mathrm{SE}=3.29,8 \mathrm{df})$} \\
\hline & & Limpets & Musse & & Limpets & Musse & \\
\hline & & $\begin{array}{l}\text { Present } \\
\text { Removed }\end{array}$ & $\begin{array}{l}\mathrm{HR}=\mathrm{T} \\
\mathrm{TR}=\mathrm{H}\end{array}$ & $\begin{array}{l}\text { Control } \\
\text { Control }\end{array}$ & $\begin{array}{l}\text { Present } \\
\text { Removed }\end{array}$ & $\begin{array}{l}\text { No alte } \\
T R=H\end{array}$ & $\begin{array}{l}\text { ive } \\
\text { Control }\end{array}$ \\
\hline
\end{tabular}

June 1994 (SNK test, Table 3). In addition, significant differences occurred among areas on both dates (Table 3). Cover values were determined by the original clumps of C. compressa for the 1993 tests and both by original clumps and the new recruits that appeared after autumn 1993 for the 1994 test. These stages could not be separated in the present experiment because the original plants were not tagged and recruits were no longer distinguishable from these on the basis of size alone for the last 3 dates of sampling

\section{Recovery of algae in the mussel habitat}

Manual removal of Patella spp. was also effective in this experiment, although temporally variable as indicated by the significant time by limpet interaction (Table 4, Fig. 5). In fact, the abundance of limpets was significantly smaller in removal than in non-removal areas after 10 and 19 mo from the start of the experiment, but not for the first date of sampling (SNK test, Table 4). The analysis also revealed that the density of limpets increased through time in areas where they were not removed (SNK test, Table 4).

There was a significant temporal decrease in the abundance of the articulated coralline algae between 3 and 19 mo from the start of the experiment, but only in plots where limpets were present (SNK test, Table 4). In contrast, temporal changes were not important where herbivores had been removed (Fig. 6A). Significant differences also occurred among areas (Table 4), indi- cating that patterns of regrowth were also variable in space for these algae. Spatial variability was, however, consistent through time since the interaction between time and areas was not significant.

Temporal changes in the coarsely branched algae also depended upon the presence of limpets (note the significant time by limpet interaction in Table 4). The removal of herbivores induced a significant increase in the percentage cover of these species by the end of the experiment. In contrast, temporal changes were not apparent in the presence of Patella spp. (Fig. 6B; SNK test, Table 4). There was no significant difference among areas, nor was there a significant interaction between areas and time.

Patterns of recovery of both Cystoseira compressa and foliose algae proceeded independently of the presence of limpets (Fig. 6C, E, Table 4). A trend towards increased abundance through time was evident for $C$. compressa, but this trend was not statisti-

Table 3. ANOVA analysis of mean percent cover of Cystoseira compressa in response to the manipulation of limpets and mussels in different areas of substratum

\begin{tabular}{|c|c|c|c|c|c|c|c|}
\hline \multirow{2}{*}{$\begin{array}{l}\text { Source of } \\
\text { variation }\end{array}$} & \multirow[t]{2}{*}{$d f$} & \multicolumn{3}{|c|}{ August 1993} & \multicolumn{3}{|c|}{ June 1994} \\
\hline & & MS & $F$ & $p$ & MS & $F$ & $\mathrm{p}$ \\
\hline Limpets = L & 1 & 361.0 & 1.2 & $>0.3$ & 0.0 & 0.0 & $>0.99$ \\
\hline Areas $(\mathrm{L})$ & 4 & 309.1 & 3.9 & $<0.05$ & 1060.4 & 4.5 & $<0.05$ \\
\hline Mussels $=M$ & 2 & 89.7 & 0.8 & $>0.45$ & 3868.1 & 8.1 & $<0.05$ \\
\hline$M \times L$ & 2 & 142.8 & 1.3 & $>0.3$ & 657.0 & 1.4 & $>0.3$ \\
\hline$M \times \operatorname{Areas}(L)$ & 8 & 112.4 & 1.4 & $>0.25$ & 480.3 & 2.0 & $>0.05$ \\
\hline Residual & 18 & 78.8 & & & 235.7 & & \\
\hline $\begin{array}{l}\text { Cochran's test } \\
\text { Transformation }\end{array}$ & & $C=0$ & $\begin{array}{l}23 . \mathrm{p} \\
\text { None }\end{array}$ & 0.05 & $C=$ & $\begin{array}{l}23, p \\
\text { Non }\end{array}$ & 0.05 \\
\hline \multirow[t]{2}{*}{ SNK test } & & & & & \multicolumn{3}{|c|}{ (Mussels: $\mathrm{SE}=6.33,8 \mathrm{df}$ ) } \\
\hline & & & & & \multicolumn{3}{|c|}{$\mathrm{TR}=\mathrm{HR}>$ Control } \\
\hline
\end{tabular}


cally significant. In contrast, significant differences among times were found for the foliose algae, these plants being more abundant after 3 mo from the start of the experiment (SNK test, Table 4). The interaction between time and areas was not significant for either group of algae.

Finally, the abundance of filamentous algae was drastically reduced by limpets in the experimental plots (Fig. 6D, Table 4), the pattern being consistent through time. Significant differences also occurred among areas, but the interaction between time and areas was not significant (Table 4).

\section{DISCUSSION}

With respect to the hypotheses posed at the beginning of the study, our results indicate that: (1) Mussels exerted a positive effect on the length of fronds of Cystoseira compressa but inhibited its recruitment. Conversely, the algal turfs had no influence on the former variable, while their effects on recruitment could not be assessed because of problems with the experimental procedure. (2) The effects of mussels were consistent across areas and they were also independent of the presence of limpets. (3) There was evidence for temporal changes in the effects of limpets on patterns of recovery of some groups of algae. (4) Patterns of recovery were homogeneous across the study site (i.e. no space-time interactions were found).

Contrasting the performance of Cystoseira compressa in the turfing and mussel habitats was problematic from the results of the present study. In fact, artifacts prevented a proper evaluation of the effects of the algal turfs on the recruitment of C. compressa, while estimation of the net effect of mussels on this alga was difficult because positive and negative interactions both occurred. It is, however, worth noting that small-scale spatial variability (between plots) in the length of fronds of C. compressa was observed in both habitats, suggesting that this could be a general feature of populations of this alga. Variability in the length of fronds might have occurred because of differences in the microhabitat where the clumps had grown. Differences due to the age of the clumps are unlikely, because these plants are fast growing and measurements were made between April and August when the recruits of the previous year had already grown into the adult stage and the new ones were yet to appear. Similar small-scale spatial variability in size has also been observed for populations of Ascophyllum nodosum along the rocky shores of the Isle of Man, UK, and in Sweden (P. A berg pers. comm.).

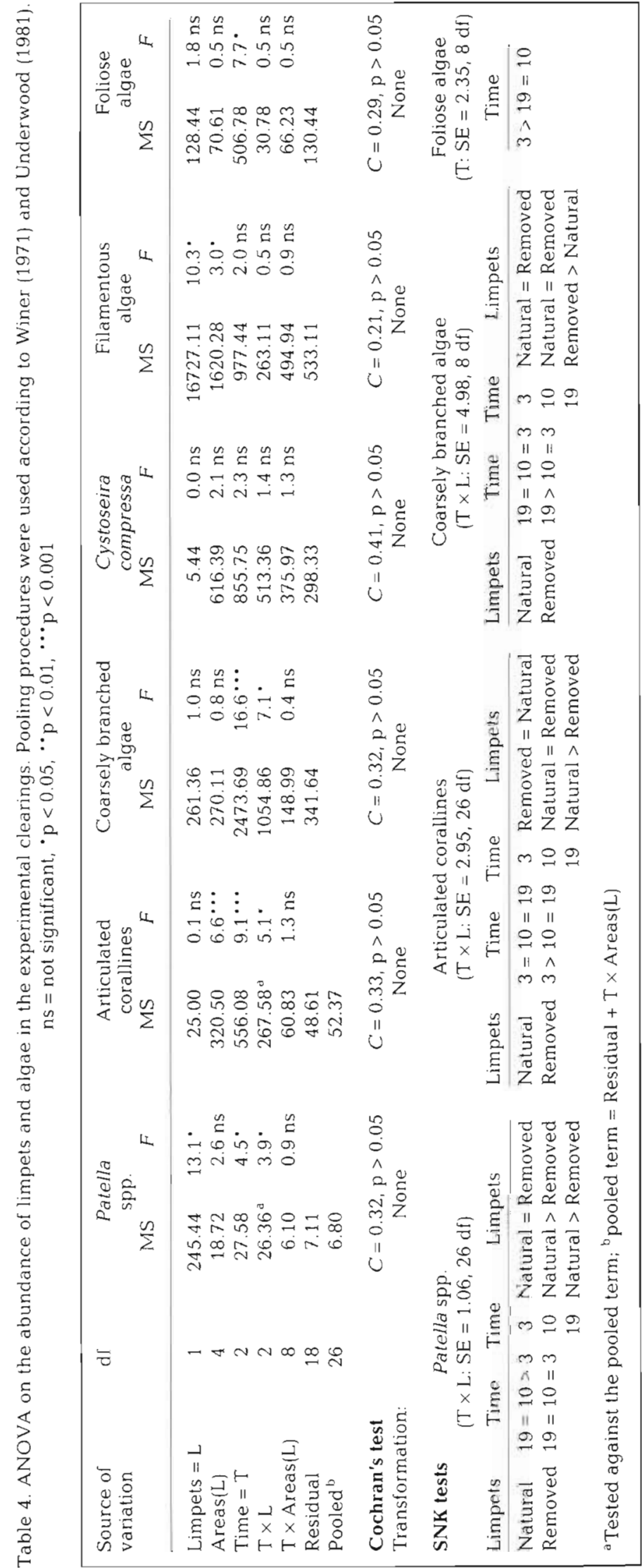




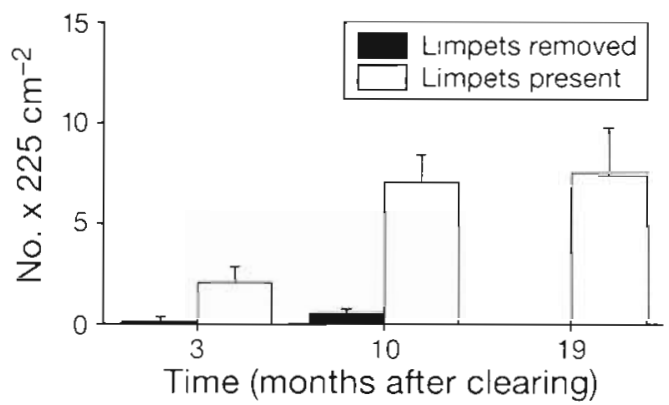

Fig. 5. Patella spp. Temporal changes in mean (+SE) density in areas where these herbivores had been removed and in areas at natural densities. Data are from 2 replicate plots pooled across 3 replicate areas

Interactions between mussels and algae have been reported several times in different parts of the world (Lubchenco \& Menge 1978, Menge 1978, Paine 1979, Suchanek 1985, Petraitis 1987. Witman 1987, McCook \& Chapman 1991). Most of these studies have highlighted the competitive dominance of mussels over algae in intertidal habitats but, as also noted by McCook \& Chapman (1991), only few of them provided formal tests of the importance of these interactions. In contrast to the prevailing pattern, these authors reported that the experimental removal of mussels had little effects on fucoid algae on rocky shores in the Northwest Atlantic. In the present study, mussels had
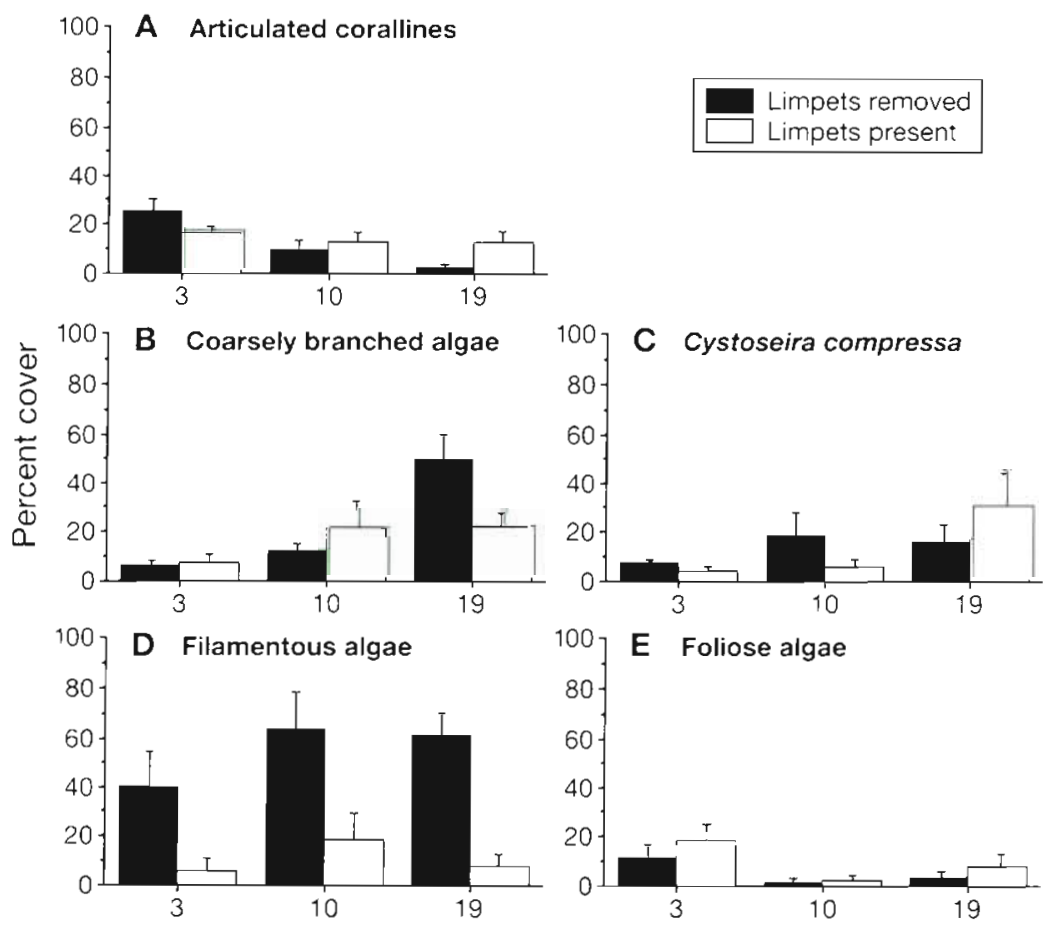

Time (months after clearing)

Fig. 6. Effects of Patella spp. on temporal changes in mean percent cover (+SE) of macroalgae from 2 replicate plots pooled across 3 replicate areas negative and positive effects on Cystoseira compressa As already stated, the removal of bivalves increased the percentage cover of the alga and this interaction was independent of the manipulation of limpets Although the contribution of the original clumps to percentage cover values of $C$. compressa could not be distinguished from that due to new recruits, recruits were abundant in plots where mussels had been removed (authors' pers obs.). Thus, inhibition of recruitment could be a plausible explanation for the differences observed between TR, HR and control plots The lack of a significant treatment by areas interaction also suggested that the effect of mussels was general for rocky shores south of Livorno.

In contrast to the patterns described above, the length of fronds of Cystoseira compressa was significantly reduced by the total removal of mussels. Inspection of Fig. 3 suggests that this effect decreased through time, but, as the study proceeded, the data incorporated either values from the original clumps or values from both the original clumps and new recruits, particularly in HR and TR plots. As a consequence, the analysis of temporal trends was difficult, but short-term effects could be interpreted more easily. The positive effect of bivalves was particularly evident in August 1993 (Fig. 3) after a long period of severe storms. Although we did not test any specific hypothesis about the effects of mussels under different hydrodynamic conditions, our results indicated that these organisms could limit the loss of biomass from clumps of C. compressa during storms. A possible mechanism could involve the stabilisation of the basal fronds of these plants, as mussels were often packed around them. The ecological importance of positive interactions has been re-evaluated recently (Bertness \& Callaway 1995); in most cases these ef fects occur under harsh physical conditions where stress-tolerant species provide suitable microhabitats for less tolerant ones (e.g. Hay 1981, Bertness \& Hacker 1994). Additional experiments are necessary to assess the net effect of mussels on the distribution and abundance of $C$. compressa under different environmental conditions.

The distribution of Patella spp. was homogeneous in the study areas and their abundance was not significantly affected by the removal of mussels. In contrast, temporal patterns were more relevant, the density of limpets increasing through time in plots where they were not removed. Some authors 
have reported that competition for space with erect macroalgae may affect the abundance of limpets, particularly in low-shore habitats (Underwood \& Jernakoff 1981). According to their results, one should expect a decrease in the abundance and/or effect of limpets during succession in areas where algal recruitment is plentiful (e.g. Benedetti-Cecchi \& Cinelli 1996). The results of the present study did not conform to this prediction, probably as a consequence of a balance between factors influencing the establishment and growth of macroalgae and factors determining their removal (including grazing). Indeed, limpets could limit the abundance of the coarsely branched and filamentous algae, the 2 most abundant groups of plants in the experimental clearings (Fig. 6). In turn, the groups which were unaffected by herbivores did not show any relevant increase in abundance during succession (rather, a significant decline in the cover of the foliose algae was found). 'Swamping effects' on limpets by erect algae were unlikely to increase with time under these conditions, at least within the period considered in the experiment.

Limpets also influenced the temporal changes in abundance of some groups of algae. The removal of Patella spp. caused a significant decrease in abundance of the articulated corallines, while a significant increase was observed for the coarsely branched. algae. The former pattern might have involved an indirect effect: limpets, by reducing the abundance of the coarsely branched and filamentous algae (the effect of herbivores was consistent through time in this case), could have provided the space necessary for the persistence of the articulated corallines. This model implies that the articulated corallines are competitively subordinate to the other groups of algae, but more resistant to grazing. Additional studies are required to assess the validity of this explanation.

The results presented here revealed similar temporal trajectories in the experimental clearings for the different areas, because no significant space-time interactions were found. The lack of such interactive effects was unexpected, because macroalgal assemblages are known to vary to a great extent at relatively small spatial and temporal scales (Astles 1993, BenedettiCecchi \& Cinelli 1994). The results of the present investigation are not directly comparable with those of most previously published studies on succession, because data here were collected independently through time allowing formal tests on temporal patterns and interactions. In synthesis, with the exception of the temporal changes in abundance induced by limpets on some groups of algae, most of the interactions examined in this study were consistent in space and/or in time. Determining in advance whether a system is highly interactive or not may help in planning future experimental and monitoring programs, since the effort and approach required may differ greatly depending upon the degree of natural variability in play (e.g. Underwood 1992). The assemblage of species dominated by mussels on the rocky coast south of Livorno seems not to be a greatly interactive system, at least within the spatial and temporal scales considered in this study.

Acknowledgements. We thank L. Airoldi, G. Ceccherelli, A. R. O. Chapman, S. J. Hawkins and M. Menconi for comments and criticism on an early draft of the manuscript. We also thank A. J. Underwood for greatly improving the final version. This work was partially funded by a MURST $60 \%$ project: the dataset was analysed and the manuscript written while L.B.-C. was supported by the El under MAST programme contract MAS3-CT95-0012 (ELROROCK).

\section{LITERATURE CITED}

Arrontes J, Underwood AJ (1991) Experimental studies on some aspects of the feeding ecology of the intertidal starfish Patiriella exigua. J Exp Mar Biol Ecol 148:255-269

Astles KL (1993) Patterns of abundance and distribution of species in intertidal rock pools. J Mar Biol Ass UK 73:555-569

Benedetti-Cecchi L, Acunto S, Nuti S, Cinelli F (1995) Modalità di distribuzione di Cystoseira compressa (Fucales. Fucophyceae) in un ambiente di transizione: un analisi sperimentale nella frangia infralıtorale a sud di Livorno. SITE Atti 16:177-179

Benedetti-Cecchi L, Cinelli F (1994) Recovery of patches in an assemblage of geniculate coralline algae: variability at different successional stages. Mar Ecol Prog Ser 110:9-18

Benedetti-Cecchi L, Cinelli F (1996) Patterns of disturbance and recovery in littoral rock pools: nonhierarchical competition and spatial variability in secondary succession. Mar Ecol Prog Ser 135:145-161

Bertness MD, Callaway R (1994) Positive interactions in communities. Trends Ecol \& Evol 9:191-193

Bertness MD, Hacker SD (1994) Physical stress and positive associations among marsh plants. Am Nat 144:363-372

Chapman MG (1995) Aggregation of the littorinid snail Littorina unifasciata in New South Wales, Australıa. Mar Ecol Prog Ser 126:191-202

Connell JH (1983) On the prevalence and relative Importance of interspecific competition: evidence from field experiments. Am Nat 122:661-669

Danielson BJ (1991) Communities in a landscape: the influence of habitat heterogenesty on the interactions between species. Am Nat 138:1105-1120

Dayton PK (1973) Dispersion, dispersal, and persistence of the annual intertidal alga. Postelsia palmaeformss Ruprecht. Ecology 54:433-438

Fairweather PG, Underwood AJ (1991) Experimental removals of a rocky intertidal predator: variation within two habitats in the effects of prey. J Exp Mar Biol Ecol 154:29-75

Hawkins SJ, Hartnoll RG (1983) Grazing of intertidal algae by marine invertebrates. Oceanogr Mar Bıol Annu Rev 21: $195-282$

Hay ME (1981) The functional morphology of turf-forming seaweeds: persistence in stressful marine habitats. Ecology 62:739-750

Hurlbert SH (1984) Pseudoreplication and the design of ecological field experiments. Ecol Monogr 54:187-211 
John MD. Hawkins SJ, Price JH (1992) Plant-animal interactions in the marine benthos. Oxford Unuversity Press, Oxford

Lubchenco J (1978) Plant species diversity in a marine intertidal community: importance of herbivore food preference and algal competitive abilitıes. Am Nat 112:23-39

Lubchenco J, Menge BA (1978) Community development and persistence in a low rocky intertidal zone. Ecol Monogr 48:67-94

McCook LJ, Chapman ARO (1991) Community succession following massive ice-scour on an exposed rocky shore: effects of Fucus canopy algae and of mussels during late succession. J Exp Mar Biol Ecol 154:137-169

Menge BA (1976) Organization of the New England rocky intertidal community: role of predation, competition, and environmental heterogeneity. Ecol Monogr 46:355-393

Menge BA (1978) Predation intensity in a rocky intertıdal community: relation between predator foraging activity and environmental harshness. Oecologia 34:1-16

Menge BA (1995) Indirect effects in marine rocky intertidal interaction webs: patterns and importance. Ecol Monogr $65: 21-74$

Menge BA, Sutherland JP (1987) Community regulation: variation in disturbance, competition and predation in relation to environmental stress and recruitment. Am Nat 130:730-757

Paine RT (1979) Disaster, catastrophe and local persistence of the sea palm Postelsia palmaeformis. Science 205:685-687

Petraitis PS (1987) Factors organizing rocky intertidal communities in New England: herbivory and predation in sheltered bays. J Exp Mar Biol Ecol 109:117-136

Robles C, Sherwood-Stephens R, Alvardo M (1995) Responses of a key intertidal predator to varying recruitment of its prey. Ecology 76:565-579

Sih A, Crowley PH, MCPeek MA, Petranka JW, Strohmeier K (1985) Predation, competition and prey communities: a review of field experiments. Annu Rev Ecol Syst 16: $269-311$

Sousa WP (1979) Experimental investigations of disturbance and ecological succession in a rocky intertidal community. Ecol Monogr 49:227-254

This article was submitted to the editor
Sousa WP (1984) Intertidal mosaics: patch size, propagule availability, and spatially variable patterns of succession. Ecology 6.5:1918-1935

Sousa WP (1985) Disturbance and patch dynamics on rocky intertidal shores. In: Pickett STA, White PS (eds) The ecology of natural disturbance and patch dynamics. Academic Press, Orlando, FL, p 101-124

Suchanek TH (1985) Mussels and their role in structuring rocky shore communities. In: Moore PG, Seed R (eds) The ecology of rocky coasts. Hodder and Staughton, London, p 70-96

Underwood A.J (1981) Techniques of analysis of variance in. experimental marine biology and ecology. Oceanogr Mar Biol Annu Rev 19:513-605

Underwood AJ (1986) The analysis of competition by field experiments. In: Kikkewe J. Anderson DJ (eds) Community ecology: pattern and process. Blackwell Scientifıc, Melbourne, p 240-268

Underwood AJ (1992) Beyond BACl: the detection of environmental impacts on populations in the real, but variable, world. J Exp Mar Biol Ecol 161:145-178

Underwood AJ, Anderson MJ (1994) Seasonal and temporal aspects of recruitment and succession in an estuarine fouling assemblage. J Mar Biol Ass UK 74:563-584

Underwood AJ, Jernakoff P (1981) Effects of interactions between algae and grazing gastropods on the structure of a low-shore intertidal algal community. Oecologia 48: $221-233$

Underwood AJ, Petraitis PS (1993) Structure of intertidal assemblages in different locations: how can local processes be compared? In: Ricklefs R, Schluter D (eds) Species diversity in ecological communities. University of Chicago Press, Chicago, p 38-51

Winer BJ (1971) Statistical principles in experimental designs, 2nd edn. McGraw-Hill Kogakusha, Tokyo

Witman JD (1987) Subtidal coexistence: storms, grazing, mutualism, and the zonation of kelps and mussels. Ecol Monogr 57:167-187

Wootton JT (1992) Indirect effects, prey susceptibllity, and habitat selection: impact of birds on limpets and algae. Ecology 73:981-991

Manuscript first received: June 25, 1996

Revised version accepted: September 30, 1996 